Mr. Sremens said if he wished to be critical he might find fault with the title of the Paper. The Author spoke of a machine for "the production of cold." Cold was the absence of heat, and it might be open to question whether it was possible to produce the absence of a thing. Refrigeration, which he thought the preferable word, meant the transfer of heat from one substance to another of the same or a superior degree of temperature, and the Author evidently agreed in that definition. The subject was one of considerable interest at the present time. Refrigerating machines were now largely used in breweries, since fermentation went on to advantage only at a temperature a little above freezing point; and to attain that point during all seasons of the year rendered artificial means of maintaining a low temperature necessary, unless native ice was employed for the purpose. For preserving meats also in hot climates and transporting it, artificial means of reducing the temperature were coming into use, and would be more extensively employed if a cheap and ready method could be devised. Refrigeration was of great importance in hot climates in a sanitary point of view, and the time was not distant, he thought, when houses and places of public resort would be refrigerated with the same care and regularity as they were now heated when necessary. He believed this might be accomplished at a cheap rate. It was stated, in the Paper, and it was an undoubted scientific fact, that mechanical refrigeration might be obtained at a cheaper rate if the reduction of temperature required were only slight than if it were considerable. Thus, an airmachine producing ice would work much less economically than one producing only cool air. In order that the subject might be more fully opened out for discussion, he proposed to refer shortly to the different methods that had been devised for producing refrigeration. There were four methods in use. The first was the old system by the evaporation of alcohol, ether, or other volatile substances. Even water when allowed to evaporate under a current of air produced refrigeration. Alcohol did so to a greater extent, and ether to a still greater extent. This method had been adopted, perhaps, for centuries; but in recent times it had been improved by Siebe and by Harrison, who had contrived that the vapour produced by evaporation should not be lost, but that it should be mechanically compressed and condensed, in order to serve over and over again. The method of producing the reduced temperature was the same in both cases, but instead of losing the ether or alcohol, a certain amount of power was expended in the improved arrangement. Another method was the chemical one of pro- 
ducing refrigeration by evaporation in connection with absorption. Many vapours-ammonia being one of them-were readily absorbed by water, but could be separated again by the application of heat to the mixed liquid. A machine on that principle was shown at the Universal Exhibition, in 1851, by M. Carré, and very good results had been realised by it. It consisted of a boiler which was filled with ammoniacal liquor, and the ammonia vapour was driven off under considerable pressure into a surface condenser composed of tubes surrounded by cool water. A separation was thus effected by heat of the ammonia from the water; and the ammonia, after being withdrawn into a vessel of lower pressure, evaporated at a very low temperature, and thus produced refrigeration, the vapours of ammonia being eagerly absorbed by water of ordinary temperature forming mother liquid for re-evaporation in the boiler. The machine was largely used, especially on the Continent; and, from information he had received, it produced a hundredweight of ice at the expense of about a shilling. An ingenious modification of this machine for small applications on board ship or for household use had been devised, consisting of two vessels connected by a pipe, but hermetically sealed. One of the vessels contained the mother liquid, which was alternately heated and cooled, to drive off the ammonia, and to re-absorb it from the second vessel, which served alternately as condenser and refrigerator for the production of ice. Another method was by the solution of crystalline substances. There were various refrigerating mixtures, one of the salts so employed being carbonate of ammoni:i, and another chloride of calcium. When crystals of chloride of calcium were dissolved in water, a considerable reduction of temperature-about $30^{\circ}$ Fahrenheit-took place. Although that would not be sufficient to produce ice from water of $60^{\circ}$ or $65^{\circ}$ temperature, an arrangement could be made by which the water to be cooled exchanged heat with the spent liquor, thus producing an accumulation of the effect in the centre of the machine. He constructed a machine on this principle many years ago, which producel ice at a considerable rate, but the salt employed-chloride of calcium-was not a pleasant substance to deal with. It had to be re-evaporated and crystallised, and this process was inferior to the purely mechanical methods which had since been adopted. The most perfect of these, as regarded cleanliness and freedom from loss, was the air machine. Atmospheric air was compressed to one half, or one atmosphere above atmospheric pressure. The compressed air was allowed to cool in contact with water, either by external application or by injection, 
and to expand again in a working cylinder. The amount of heat that disappeared in the second working cylinder was the exact measure of the refirigeration produced, and it could be easily calculated; whereas the power expended was the difference of force involved in compressing the air at a higher and of expanding it at a lower temperature. In 1857 a machine of that description was invented by Dr. Gorrie, an American, and was brought to London. Mr. Siemens was asked to report upon it. The machine did not produce satisfactory results. The engine was a good one, and the air-pump was judiciously constructed; but the connection between the reservoir containing the compressed air and the air-expansion engine was too narrow, and was provided with a throttle valve, there being evidently a vague idea in the mind of the inventor that the air would produce more refrigeration in expanding spontaneously without doing work than in expanding behind a working piston, an idea which was permissible at that time when the dynamical theory of heat was little understood. That was one of the defects which he pointed out. Another was that the hot or compressed air was not sufficiently cooled before it was expanded, and was not deprived of its moisture. The moisture in air played a considerable part in those machines. At a temperature of $65^{\circ}$ Fahrenheit saturated air contained 1 per cent. of vapour of water, and this had not only to be reduced into the liquid, tut also into the solid condition, representing a total absorption of heat to the amount of 1,140 units of heat per lb. of condensed vapour, which, upon the quantity of air, would represent $15^{\circ}$ Fahrenheit of loss in the effect produced by the expansion. He believed, if these faults had been remedied, the machine would have given satisfactory results. Since that time a German engineer, Mr. Windhausen, had constructed machines on similar principles, and had, after many fruitless attempts, obtained remarkable results. It was stated, at a meeting in connection with the Vienna Exhibition, that a machine of $150 \mathrm{HP}$. produced $30 \mathrm{cwt}$. of ice per hour, the theoretical result being that that amount ought to be produced by $90 \mathrm{HP}$. The cost of producing a hundredweight of ice by this machine was stated to be one shilling-a similar result to that obtained in M. Carré's machine. The machine described by the Author of the Paper was also an air machine-a reversed air-engine, so to speak-and therefore, in a certain sense, analogous to those he had before mentioned. The Author did not compress the air, cool it, and then transfer it into a separate cylinder to be re-expanded, but he combined these 
operations in an engine similar, in every way, to Stirling's air-engine, on a supposition that that was the most perfect airengine known, and that, in inverting it, he would be likely to obtain the best result of refrigeration. He could not, however, agree in the opinion that the Stirling engine was a perfect one. It was the first engine containing a regenerator; but (as he had pointed out in a Paper read before the Institution in 1853) it realised at most only from one-fifth to one-sixth part of the theoretical duty of the heat expended. The reason was that all the air cooled and heated alternately did not enter the working cylinder; but the diagram of the force obtained in the working cylinder formed only a sixth part of the diagram that would be produced if the whole of the air were allowed to expand behind a working piston and between the same limits; and that proportion really indicated the dynamic value of the engine. Therefore, although he admired the ingenuity with which the Author had enlarged the available heating surfaces of Stirling's arrangement, and elaborated the best form of regenerator for the purpose, he could not agree in the application of that principle to refrigeration. He believed better results would have been obtained if the compressing apparatus had been separated from the expanding apparatus as had been done by others. That opinion appeared to be corroborated by the results given in the Paper. With $37 \mathrm{HP}$. 20 gallons of water were reduced from $61^{\circ}$ to $47 \frac{1}{4}^{\circ}$ per minute, which was equal to $2.8 \mathrm{lbs}$. of ice per hour, whereas the Windhausen engine was said to produce $20 \mathrm{lbs}$. of ice with $1 \mathrm{HP}$. Generally speaking, he believed the air-compressing engine, on the purely mechanical mode of producing refrigeration, was applicable with the greatest advantage where moderate refrigeration was required. Where the production of ice in large masses was desired, he believed the method adopted by Siebe, and by Harrison was superior, for this reason: in compressing and expanding air, 25,000 cubic feet of air were required to produce the effect of $1 \mathrm{lb}$. of ice; whereas, in compressing sulphuric ether after evaporation, only 5,100 cubic feet were required, the reason being that when sulphuric ether was transferred from the liquid into the gaseous condition, the whole of the latent heat was obtained. A much higher result was arrived at by using a still more volatile substance -methylic ether-which at a depression of temperature equal to $15^{\circ}$ Centigrade had a pressure of $1 \frac{1}{2}$ atmosphere, and the displacement of piston to produce the same effect was only about 340 cubic feet. Therefore a pumping-engine, with a displacing capacity of piston of 340 cubic feet per minute, would produce 
the same effect as an air engine of 25,000 cubic feet displacement per minute, and of 5,000 cubic feet in the case of a sulphuric ether engine. This meant a much smaller engine and a less costly machine in the case of the methylic ether pump, although the expenditure of power might be the same; but, on the other hand, there was the set-off of having to deal with a highly infammable material like methylic ether instead of with atmospheric air. For producing a depression of temperature in houses or breweries he believed the air-engine was the best contrivance that could be adopted.

Mr. H. J. West said, though the Paper was on the mechanical production of cold, it only gave a description of apparatus invented by the Author. It was a matter for regret that the subject was not more extended, so as to embrace other kinds of air machines, and the class of apparatus in which cold was mechanically produced by the evaporation of water, ammonia, or ether. The scope of the discussion was narrowed by the omission of all reference to the work done by the ether machine at Bathgate, or by other descriptions of machinery, or by comparison between such and the Author's engine. The Author had stated that the inflammability of ether was one of the reasons why the machine at Bathgate was disused. 'The late Mr. D. E. Siebe and himself had often remarked upon the circumstance that the ether machine, which it was admitted had done good service, was in constant work up to the time when Mr. Kirk introduced his apparatus, when the inefficiency of the ether machine appeared to become discernible. He was glad now, after the Author's statement, to be able to correct that impression. With regard to the objection on the ground of the inflammability of ether, he night remark that paraffin was inflammable, and so was alcohol, yet the one was burned and the other was drunk. Coal gas was inflammable, but that was no objection to its use even near a fire. In the ether apparatus manufactured by his firm (of which there were fifty or sixty in use in breweries, paraffin, and oil works), it was a common practice to test the joints by a lighted candle. The injection of water and brine into the hot and cold ends of the cylinder was not, as claimed by the Author, a new improvement, but had been included in previous patents. ${ }^{1} \mathrm{As}$ a refrigerative agent, ether possessed great advantages over the air system, for these reasons: to produce cold by air it was necessary first to compress the air to 50 lbs. to 100 lbs. on the square inch,

1 Newton's specification, No. 13,234-1850.

Mignot's " No. 1,579-1870. 
and then to cool it previous to expansion; but cold was at once obtained by the simple expansion of ether vapour, and the preliminary processes of high compression and cooling, as in the case with air, were consequently avoided. In the trial of the machine at Oak-bank the horse-power indicated was 37 , and the quantity of water cooled per minute was 20.6 gallons, or 1,236 gallons an hour, $14^{\circ}$. The quantity of cooling or condensing water was about equal to the amount cooled in the engine-a far too large amount to be used for the purpose. With some of the machines of his firm, now in use in large breweries, more than six times the amount of work done by the machine at Oakbank could be accomplished by 50 or $60 \mathrm{HP}$. The brewers complained of even that amount of power being expended; but how inuch more would they complain of $122 \mathrm{HP}$., which Mr. Kirk's machine would require for the same duty? Such a heavy fuel tax and expenditure of force, as compared with the results obtained, would prohibit their further use. The Author had displayed great ingenuity and ability in the construction of his apparatus, and, with some modification, it would be one of the best air machines in use.

Mr. Imray said, in looking at the figures given with regard to the dry-air machine, it appeared that in heating the cooling water applied to it what might be called 1,376 Joule's equivalents were effected, i.e., 1,376 lbs. of water heated one degree. 'I'his, according to the ordinary estimate of 772 feet of work done per lb. degree of water heated, would give a power of 32 horses. Agxin, he extracted from the brine an amount of heat equivalent to $549 \mathrm{lbs}$. of water cooled $1^{\circ}$, which, reckoned according to Joule's equivalent, gave $13 \mathrm{HP}$. The difference between this cooling of the brine and the heating of the cooling water amounting to 19 HP., was what the engine did; and, considering that it was working at $23 \mathrm{HP}$., there appeared to be 83 per cent. of efficiency. Taking the figures in the same way with the wet machine the efficiency was only 40 per cent. As $1 \mathrm{lb}$. of coals in an ordinary boiler would boil off $10 \mathrm{lbs}$. of water, it ought to produce $234 \mathrm{HP}$.; but $1 \mathrm{lb}$. of coals, with the best engine working with $2 \frac{1}{2}$ lbs. of coal per HP. per hour, would only give $60 \mathrm{HP}$. instead of $2 \frac{1}{2}$ times 234 , i.e., only 10 per cent. of the heat put into the water. 'The greater part of the heat was wasted, going off as latent heat with the waste steam. A machine giving 83 per cent. of efficiency from the working of a piston would be a most valuable one. He regretted Mr. West had not given such data with regard to his ether machine as would enable a comparison to be instituted 
between the two. The ether machine ought to be better than the other, because in condensing ether the pressure was got rid of altogether when it attained the liquid state. He was surprised at the statement that $1 \mathrm{cwt}$. of ice could be produced for $1 \mathrm{~s}$. That meant, taking water at $52^{\circ}$, that it was reduced $20^{\circ}$, and $140^{\circ}$, the latent heat of ice, altogether $160^{\circ}$, which was equal to 18,000 Joule's equivalents; and that, according to the usual reckoning, would require $1.8 \mathrm{lb}$. of coal to produce it. That was a large efficiency indeed. He did not question the statement, but should be glad to know how the efficiency was obtained.

Mr. L. Olrick said he had notes of some careful experiments made at Truman's brewery by the engineer, Mr. King. From these it would appear that eighteen barrels of water, each weighing $360 \mathrm{lbs}$, were cooled $10^{\circ}$ by using $4 \mathrm{cwt}$. of ice. Each pound of ice, in being converted into water of a final temperature of $51^{\circ}$, absorbed 161 units of heat; and 4 cwt., or 448 lbs., multiplied by 161, gave 72,300 units of total heat absorbed. Eighteen barrels of water, in cooling down $10^{\circ}$, would give off but 58,800 units, showing a deficiency of 13,500 units, which must have been absorbed by the vessel containing the water, or by the cooling effects of the atmosphere. Truman's machine could produce 6 tons of ice in twenty-four hours, or 5 cwt. per hour; in other words, it could cool twenty-two and a half barrels of "liquor" per hour $10^{\circ}$, or $81,000 \mathrm{lbs} .1^{\circ}$ per hour. Comparing this result with that obtained when the machine was employed merely to cool water to be used in the ordinary refrigerators, Mr. King found that the machine was capable of reducing the temperature of twenty-six barrels of water hourly $23 \frac{1}{2}^{\circ}$, or six hundred and eleven barrels $1^{\circ}$, that was to say, capable of absorbing 219,960 units of heat per hour. 'This gave an efficiency of 2.8 times as much as by making the ice first. Unfortunately there were no indicator diagrams taken from the engine that drove the machine, but the coal consumed to produce one ton of ice was $4 \frac{1}{2} \mathrm{cwt}$., which was equal to producing 4.44 lbs. of ice per lb. of coal. There was a difficulty in comparing different machines because the requisite data were not given. In some notes as to Mr. Siddeley's machine at Reid's brewery the indicated horse-power to drive it was 25 , and thirty barrels were cooled per hour from $55^{\circ}$ to $33^{\circ}$-i.e., $3,960 \mathrm{lbs}$. $1^{\circ}$ per minute. In the particulars of Mr. Kirk's machine no indicated horse-power was given, but his largest machine cooled forty-five barrels $15^{\circ}$ per hour, or $4,050 \mathrm{lbs} .1^{\circ}$ per minute. A French machine by M. Carré was said to produce from $8 \mathrm{lbs}$. to $15 \mathrm{lbs}$. of ice per pound of coal; but no data were given to check the 
calculation. For every pound of ice $10 \mathrm{lbs}$. of water were required. In making ice he believed Mr. Kirk's machine was not so efficient as some others. At Messrs. Young's, at Bathgate, it only made 1 ton of ice per ton of coal used. During the last two years a machine by Mr. Reece appeared to be far more efficient than any other. According to experiments tried: and reported upon by Professor Foster, 1,000 lbs. of ice were produced by a consumption of $50 \mathrm{lbs}$. of coal, and the water consumed was 4,000 gallons. The work was done in about three hours. Thus 20 tons of ice could be produced by 1 ton of coal. But the condensing water amounted to 800 tons, which seemed out of proportion to the quantity used by other machines. He did not approve of the title of the Paper, because in the majority of ice or refrigerating machines, as at present constructed, the power employed did not produce the cold, but only conveyed it, that was, took it out of one substance and forced it into another; hence the number of units of heat abstracted from, say water, might be many times greater than the number of units used to drive the engine. The number of units of heat abstracted should, however, be found in the water which the machine threw off. A common surface condenser with its circulating pump was a complete refrigerating machine to all intents and purposes; but the number of units of heat abstracted from the steam greatly exceeded the number of units employed to drive the circulating pump. The waste thrown out from refrigerating machines was twofold: exhaust steam from the engine, and hot water from the condenser. The smaller the collective cost of these two items for the work done, the better, of course was the machine.

Mr. REEs REECE said the machine devised by the Author was the most complete one of its class yet constructed; but he did not know why the mechanical production of cold as applied to air had been distinguished from that applied to ether, each being a method of producing cold by mechanical means. He could bear testimony to the efficiency of the machine at Bathgate, and he had also seen one of these machines of the same size at another place, where the results were practically the. same. On the compressing side of the machine a quantity of heat was evolved, which was sufficient to heat $1,376 \mathrm{lbs}$. of water through $1^{\circ}$, and the compressed air in expanding cooled $609 \mathrm{lbs} .1^{\circ}$. The relation existing between 609 and 1,370 was the relation absolutely existing between the capacity for heat under constant volume and the capacity for heat under constant pressure. Reducing 1,376 into horse-power, it appeared that $32 \cdot 2$ HP. was exerted on the compressing side of 
the machine; and 609 , on the other side, would give 14.22 HP. Assuming the two engines to be working apart, $32 \cdot 2 \mathrm{HP}$. was expended on the one side in compressing air, and on the other, 14.22 HP. was recovered back. The difference between these two would be the energy required to produce a given amount of refrigeration. In Mr. Kirk's machine 609 heat units was the amount of cold produced, and it was easy to arrive at the work that could accomplish as a refrigerating agent. $\mathrm{He}$ found in practice, and after considerable experience, that it took $200^{\circ}$ of heat to freeze $1 \mathrm{lb}$. of water at $70^{\circ}$, allowing for waste of radiation. This would give just $3 \mathrm{lbs}$. of ice per minute, or $180 \mathrm{lbs}$. per hour. Taking $18 \mathrm{HP}$. of theoretical force, a perfect engine would give $10 \mathrm{lbs}$. per horse-power. Mr. Kirk had found the friction $5 \mathrm{HP}$. in excess of that-i.e. $23 \mathrm{HP}$. In that case the production would be 2.65 lbs. per minute per horse-power, or 159 lbs. per hour; or $7 \cdot 3 \mathrm{lbs}$. per horse-power, friction included. The difference therefore between a perfect engine and the Author's results was as $7 \cdot 3$ is to 10. The conclusions arrived at by Mr. Siemens in reference to Windhausen's machine, differed from his observations. A large Windhausen machine working for some hours produced 560 lbs. of ice for every 96 indicated horse-power transmitted by the engine, being somewhat over $5 \cdot 6 \mathrm{lbs}$. per horse-power. He did not think it would be possible to improve the air machine much beyond what had already been done, unless the relation existing between the capacity for heat under constant pressure and constant volume were wrong. 'The relation existing between 609 and 1,370 was as nearly as possible the relation existing: between 1,424 and 424 ; and there was here a fair and substantive statement of mechanical equivalent of heat as applied to a perfect machine. In Mr. Kirk's machine the medium used was atmospheric air, and the mechanical energy was the means by which the cold was generated. But there were other methods by which mechanical energy could be used for the production of cold; such, for example, as the evaporation of liquids in what was wrongly called a vacuum. In evaporating a liquid by removing the atmospheric air, the vapour of the liquid became the substitute for that of the air. This might be said to be the nature of ether machines, so called, and the principle on which they were founded might be thus stated. Dalton found that the tension of the vapour of liquids was proportional to the distance of their boiling point in air, and the distance from which they were made to boil was the weight of the vapour which the pump was enabled to throw over. Taking water at $100^{\circ} \mathrm{C}$. and ether at $35^{\circ} \mathrm{C}$, the tension of their vapour would be the same, if evaporated 
at $30^{\circ} \mathrm{C}$. lower, that was the water at $70^{\circ} \mathrm{C}$, the ether at $5^{\circ} \mathrm{C}$. The tension of their vapour would then be $\cdot 3$ of an atmosphere. Evaporating ether at $41^{\circ} \mathrm{Fahr}$. by means of an air-pump, the tension of the vapour of ether, according to Dalton's law, and according to the direct experiments of M. Regnault, was 3 of an atmosphere; and as a cubic foot of ether under ordinary pressure weighed $2 \cdot 58$ ounces, the weight of it at $41^{\circ}$ would be as nearly as possible one avoirdupois ounce. Taking the same ether and evaporating it at $14^{\circ}$ Fahr., that was at $-10^{\circ} \mathrm{C}$, the atmospheric pressure would be $\cdot 156$ of an atmosphere, and the weight of the cubic foot would be exactly half an ounce. Evaporating at zero Fahr., the weight would be $\cdot 36$ of an ounce. In the application of these figures to the evolution of heat by means of ether at various temperatures, with an air-pump of 10 feet cube, running at 40 revolutions a minute, 400 ounces of ether would be evaporated at $41^{\circ}, 200$ ounces at $14^{\circ}$, and 144 ounces at zero. A good deal had been said as to the difference caused by using ice for cooling directly and using water at an elevated temperature. The gain was that which he had stated. Evaporating the 400 ounces in the ether machine, taking the temperature of the condenser to be $85^{\circ}$, the first work of the machine was to reduce the temperature of the ether to $41^{\circ}$, which would require 14 per cent. of the whole ether. Reducing the temperature to $14^{\circ}$, it would take 22 per cent. of the whole ether, and reducing it to zero, 30 per cent.; so that an ether machine having an airpump 10 feet, the double stroke running 40 per minute, the real and useful working would be as follows:-

$\begin{array}{ccc}\text { Temperature. } & \text { Real evaporation. } & \text { Useful evaporation. } \\ 41^{\circ} \text { Fahr. } & 400 \mathrm{oz} . & 344 \mathrm{oz} . \\ 14^{\circ} " & 200 " & 156 \% " \\ \text { Zero } & 144 ", & 99 \cdot 8 \mathrm{oz} .\end{array}$

Taking a cylinder manufacturing ice at $14^{\circ}$ and cooling water at $41^{\circ}$, the relative proportion of evaporation would be as 344 to 156 .

$\mathrm{He}$ now came to another method of applying cold, independent of mechanical power. All that was required was to burn : given quantity of coal under a steam boiler, and the energy produced by that coal was the whole energy required. Mr. Philip Ferdinand Carré, fourteen or fifteen years ago, when engaged in the construction of ether machines, finding it difficult to carry them through, was led, after some researches of M. Regnault, to construct an ammonia, machine. Mr. Carré took a quantity of strong solution of ammonia, and boiled it over and into a condenser. He found, as others had done since, that $100 \mathrm{lbs}$. of strong solution of ammonia, boiled by a distillation up to 5 per cent., yielded 
75 per cent. of ammonia, and 25 per cent. of water. This being condensed would be used effectively for refrigerating purposes. The only drawback was that the liquor condensed contained 25 per cent. of water, and holding a large quantity of ammonia made the machine intermittent and relatively costly, but not nearly so costly as an air or ether machine as a method of producing cold. The French Academy appointed a commission to investigate the subject, and that commission pointed out the want of complete success in the machine, stating that what was required was a method by which ammonia could be had nearly anhydrous on one side, and an exhaust liquor on the other free from ammonia. This led him to study the problem, and he would briefly state what he had done. By mixing two liquids together of different boiling points, one liquid could be separated thoroughly and perfectly from the other. When alcohol was mixed with water up to 5,10 , or 20 per cent., by a process of fractionation, the two could be separated; and it occurred to him that he could thoroughly remove the whole of the water contained in the mixture, and obtain on one side of the instrument ammonia free from water, and on the other side water comparatively free from ammonia. This he had been enabled to do, and the ammonia obtained in this way, passing through a condenser without the aid of any mechanical energy, was condensed simply by its own accumulation, and a current of cold water passing round it. Passing that ammonia into a refrigerator, he connected it to an absorbing vessel containing water or exhaust liquor; and simply opening a cock connecting them was sufficient for it to resume its aëriform condition, without the aid of any mechanical force, the gas being removed by its solution in the liquor of the absorbing vessel. In the case of the ammonia, the same as the ether, a portion of the work of the refrigerator was to reduce the temperature of the ammonia from that of the condenser to that of the refrigerator at its working temperature. Instead, as in the case of the ether, using from 14 per cent. to 30 per cent., he found, in reducing it to $41^{\circ}$ he used $2 \frac{1}{2}$ per cent., in reducing it to $14^{\circ} 4$ per cent., to zero 5 per cent. For every $1 b$. of ammonia thus liquefied in the liquefactor, $920^{\circ}$ of heat were given out, i.e., it heated $920 \mathrm{lbs}$. of water through $1^{\circ}$. In the evaporation of the same quantity of ammonia it cooled down $920 \mathrm{lbs}$. of water through $1^{\circ}$. At whatever temperature it worked the cost of refrigeration was the same; by means of ammonia, therefore, cold could be produced at the cheapest possible rate. The relation existing between ammonia and ether was the relation between 168 and 920 , irrespective of the mechanical energy required. There was one other advantage in 
the use of ammonia. When the temperature of the cooling cylinder was reduced 30 below zero, it had still a mechanical energy and force equal to that of water at 212, and going down further, $10,15,20,30,40,50$, and even a temperature of 60 degrees below zero of Fahr., it would be as energetic an instrument as at any higher temperature, whilst all others deteriorated in efficiency as the temperature fell. Taking a pound of coal and burning it clean under the same boiler, 8,500 heat units would be transmitted to the water. Using that to work a good air machine, $200^{\circ}$ of heat would be absorbed; in the ether machine, $600^{\circ}$; in the ammonia machine, $4,000^{\circ}$. These differences showed the real economy of the different systems. It was essential that the machines, whatever system was adopted, should be well constructed.

Mr. David 'Гhomson said, when he first had occasion to pay attention to this subject two or three years ago, he found much difficulty in getting reliable, and practically available, information on the theory of the production of cold by mechanical means, without understanding which it was impossible to ascertain in what direction improvements might be looked for, or to estimate to what extent they might be carried. Even during the present discussion little had been said on the theoretical part of the subject in such a form that it could be applied in practice.

According to the theory of thermo-dynamics, there was a point so low in the thermometric scale that all heat was there considered to be absent. This point was reached $461^{\circ}$ below the zero of Fahrenheit's scale; and temperatures measured from this real zero were called absolute temperatures. It followed that the absolute temperature of any substance was its temperature as measured by Fahrenheit's thermometer plus $461^{\circ}$.

This being understood, let the absolute maximum temperature of the air in the hot or compression end of the cooling machine be expressed by

The absolute minimum temperature of the air in the cold or expansion end of the machine be expressed by

Also let it bo supposed that the machine was theoretically perfect, that it worked without mechanical friction, that it neither received heat from nor radiated heat to surrounding objects, and that it conducted no heat through its own substance from the hot to the cold end.

On this supposition let the cooling work done, expressed in pounds of water cooled $1^{\circ}$ Fahrenheit (the British thermal unit), be denoted by . . . C 
Let the power (expressed in foot lbs.) required to do the cooling work $\mathrm{C}$, by the supposed perfect machine, be denoted by . . . . . P

"Then, by the received principles of thermo-dynamics,

$$
\mathrm{P}=772 \mathrm{C} \times \frac{\tau_{1}-\tau}{\tau} \cdot \quad \cdot \quad . \quad . \quad \text {. }
$$

or conversely,

$$
\mathrm{C}=\frac{\mathrm{P}}{772} \times \frac{\tau}{\tau_{1}-\tau}
$$

The power by these formulæ for any given cooling work was, of course, smaller than could be attained in practice; but they, nevertheless, were useful in showing the limit short of which all practical efforts must stop, and they afforded a useful means of estimating the degree of efficiency which any given machine had attaired. It was desirable to notice the important bearing that the quantity $\tau_{1}-\tau$ had in determining the power which, it would be observed, increased in either the same or a more rapid ratio, than this difference between the temperature of the two ends of the machine.

The improvement which Mr. Kirk had made in the new wet air as compared with the original dry-air machine was thus readily understood. Dry air was a very bad conductor of heat, and to enable the necessary amount of heat to be transmitted through the iron plates from the air to the water, or vice versâ, required that the air at the hot end should be much hotter than the water that carried off the waste heat; and that the air at the cold end should be much colder than the water or brine that was being cooled. The difference of temperature between the air at the two ends of the machine $\left(\tau_{1}-\tau\right)$ was thus much greater than if there had been an easier transfer of heat between the air and water. Mr. 'Thomson thought, from experiments he had made, that this difference of temperature must be considerably more than Mr. Kirk supposed. The formula A showed that this must cause a great addition to the power required to work the machine; and that the wet-air machine, where the air and water came into intimate contact with each other, must, by diminishing the difference of temperature between them, be able to work with less power. The trials of the machines described in the Paper proved that this was the practical result to a great extent.

One of the most characteristic peculiarities of Mr. Kirk's cooling machines was the use of what were termed "regenerators"-a 
name derived from Stirling, who was the original inventor of them, as applied to his hot-air engine. The object and effect of these appendages had sometimes been misunderstood. Theoretically, a machine constructed to work without them ought to be as efficient as one made to work with them. But tho regenerators gave these great practical advantages: they enabled the cooling effect of each stroke of the machine to commence at the point where the last left off; that was, if one stroke cooled the air $10^{\circ}$, the next stroke might cool it an additional $10^{\circ}$, and so on, and thus admit of the temperature of the air being lowered to any required degree without the excessive variations of pressure that would otherwise be required. By their means also the machine was enabled to work constantly with the same air, which could therefore without practical difficulty be of any desired density; and this, as had been remarked, was an important point. That the conclusion derived from the original experiments was correct, to the effect that the system of regenerators was the most likely to yield good practical results, was proved by the fact, that since then two persevering attempts on a large scale, with an expenditure of ample means, had been made, by Mignot and by Windhausen, to compete with Kirk's machines by means of air machines without regenerators; but both had failed to obtain equally good results.

For the sake of simplicity, the formule $A$ and $B$ had been spoken of as applying to air machines only; but by the received principles of thermo-dynamics it was readily proved that they applied equally to all cooling machines, no matter whether they operated by means of air, ether, ammonia, or any other fluid. In so applying them, it was to be understood that $\tau_{1}$ and $\tau$ were the highest and the lowest absolute temperatures of the working fluid at the hot and the cold ends of the respective machines. Also, in the ammonia machine, or others working on the same principle, it was to be observed that no mechanical power being applied, $P$ must be understood to denote the amount of heat that was theoretically required at the rate of 1 heat unit to 772 foot lbs. of power. In other words, the formula $A$ for an ammonia machine would become-heat required to do the work $C=C \frac{\tau_{1}-\tau}{\tau}$. The relative merits of cooling machines made on the different systems that had been described could not therefore be determined by purely theoretical considerations, from which point of view all were equal.

The principal defect of the air machines, besides the bad con- 
ducting power of air, and its effects as already described, was due to the circumstance that the comparatively small theoretical power required to do the work was the excess of the power required to compress the air beyond that given out during its expansion; and both of these were large compared with theif difference, as was shown in the Paper. This necessitated the strength and working friction of the machine being such as were due to two powerful engines working against each other, in order to utilise a comparatively small difference of power. In this respect the ether machines had so great an advantage that it was not probable that air machines could successfully compete with them where economy of power alone was considered.

The ammonia machines had, theoretically, a great economical superiority, in heat being so much cheaper than its equivalent of mechanical power; but the practical difficulties involved in their use were so great, that he had not been able to learn that such machines had yet been made to work efficiently and regularly for considerable periods. ${ }^{1}$ There was this difficulty attending

1 If $\mathbf{P}$ is taken as equal to $1 \mathrm{HP}$. working one minute, or 33,000 lbs. raised 1 foot high,

$$
\mathrm{C}=\frac{33.000}{77^{2}} \times \frac{\tau}{\tau_{1}-\tau}=42 \cdot 733 \frac{\tau}{\tau_{1}-\tau} .
$$

This form of the formula was a convenient one for testing the efficiency of the different machines, whose performance had been referred to in the Paper or in the Discussion. In applying it to this purpose it is to be observed that, if a cooling machine were perfect, the temperature of the wolking fluid would be the same as thal of the water passing from the hot and cold ends of the machine. This of course could never be the case in practice, but to whatever extent the actual temperatures of the working fluid were different from those of the water it acts on, to the same degree this constituted an imperfection in the machine; and therefore, in measuring its efficiency as compared with a perfect macline, the maximum and minimum temperatures of the working fluid $\left(\tau_{1}\right.$ and $\tau$ in the formulæ) should be taken as the same with those of the water or brine passing from the hot and cold ends of the machine.

This had been done in the following examples; and the specific heat of brine per gallon had been taken as 11 instead of 10 for pure water. Probably the specific heat of brine was hardly so high, but the difference could be of no practical importance in these examples.

Mr. Kirk's trial of the dry-air machine at the Bathgate Works :

Here

$$
\begin{aligned}
& \tau_{1}=94+461=555 \\
& \tau=23 \cdot 5+461=484 \cdot 5 \\
& \tau_{1}=\tau \\
& \frac{\tau}{6}=\frac{484 \cdot 5}{60 \cdot 5} \\
& \frac{\sigma 0 \cdot 5}{\tau_{1}-\tau}=8 \cdot 0 \\
& C=6 \cdot 7 \times 11 \times 8 \cdot 5=626 \cdot 45 \text { heat units. } \\
& P=23 \text { Indicated HP. }
\end{aligned}
$$


the use of ammonia, that, for this climate, it required for making ice to work with a pressure of 160 to $170 \mathrm{lbs}$. on the square inch, and in hot countries $200 \mathrm{lbs}$., and with machines working at those high pressures it was almost impossible to keep them absolutely tight.

Therefore the cooling effect produced per horse-power per minute

$$
=\frac{626 \cdot 45}{23}=27 \cdot 2 \text { heat units, }
$$

and the cooling effect that would have been produced by a perfect machine per horse-power per minute

$$
=42 \cdot 733 \times 8=342 \text { heat units. }
$$

The efficiency of the machine was therefore $=\frac{27 \cdot 2}{342}=\cdot 08$, that of a perfect machine being 1 .

Mr. Kirk's five hours' trial of the wet-air machine at the maker's works :

Here

$$
\begin{aligned}
& \tau_{1}=81+461=542 \\
& \tau=47 \cdot 25+461=508 \cdot 25 \\
& \tau_{1}=\tau=\frac{33 \cdot 75}{\tau}=\frac{508 \cdot 25}{33 \cdot 75}=15 \\
& \frac{\tau}{\tau_{1}-\tau}=15 \cdot 6 \times 10 \times 14=2884 . \\
& \mathrm{C}=20 \cdot 6 \times 1 \text { Indicated HP. }
\end{aligned}
$$

Therefore the cooling effect produced per horse-power per minute

$$
=\frac{2884}{37}=78 \text { heat units, }
$$

and the cooling effect that would have been produced by a perfect machine per "horse-power per minute

$$
=42.733 \times 15=640 .
$$

The efficiency of the machine was therefore $=\frac{78}{640}=\cdot 12$,

that of a perfect machine being 1 .

Mr. Kirk's trial of the wet-air machine (the same as in the last trial) in ordinary work at the Oakbank Works:

Here

$$
\begin{aligned}
& \tau_{1}=73+461=534 \\
& \tau=28 \cdot 25+461=\frac{489 \cdot 25}{44 \cdot 75} \\
& \tau_{1}=\tau=\tau \\
& \frac{\tau}{\tau_{1}-\tau}=\frac{489 \cdot 25}{44 \cdot 75}=11 \\
& C=13 \cdot 05 \times 11 \times 8 \frac{3}{4}=1256 \text { heat units. } \\
& P=25 \text { indicated HP. }
\end{aligned}
$$

Therefore the cooling effect produced per horse-power per minute

$$
=\frac{1256}{25}=50 \text { heat units, }
$$

and the cooling effect that would have been produced by a perfect machine per horse-power per minute $=42.733 \times 11=470$ heat units. 
An engineer accustómed to steam engines working at equally high pressures might naturally suppose that that pressure was nothing to speak of; but it should be borne in mind that an amount of leakage, that, in an ordinary steam engine would be thought nothing of, would be absolutely fatal to an ammonia machine, owing to the poisonous character of the ammonia, and the expense and trouble of renewal. The great thing was to have a machine that would work continuously, and tnat, as far as he had been able to ascertain, was not the case with ammonia machines. The ether machines described by Mr. Siddeley were erected under contract by the firm with which he was connected, and he was able to confirm from personal observation the figures which $\mathrm{Mr}$. Siddeley had quoted as showing the results of their working. Thero need be no further doubt upon the subject, as he was authorized to say by the kindness of Mr. Wilson, the chief brewer at Messrs. Coombe's, that any member of the Institution, or any gentleman feeling an interest in the subject, would be permitted to test the machines in any way they chose, if they did not interrupt the regular work of the brewery; and for this purpose a Richard's indicator, thermometers, \&c., would be provided.

The efficiency of the machine was therefore $=\frac{50}{470}=\cdot 1$, that of a perfect machine being 1 .

Trial of an ether cooling machine at Combe's Brewery, as given by Mr. Siddeley :

Here

$$
\begin{aligned}
& \tau_{1}=83+461=544 \\
& \tau=47 \frac{1}{2}+461=508 \frac{1}{2} \\
& \tau_{1}=\tau \\
& \frac{\tau}{\tau_{1}-\tau}=\frac{508 \cdot 5}{36 \cdot 5}=14 .
\end{aligned}
$$

165 barrels per hour is equal to

and

$$
\frac{165 \times 36}{60}=99 \text { gallons per minute, }
$$

$$
\begin{aligned}
& \mathrm{C}=99 \times 10 \times 7 \frac{1}{2}=7 \pm 25 \text { heat units. } \\
& \mathrm{P}=30 \text { indicated HP. }
\end{aligned}
$$

Therefore the cooling effect produced per horse-power per minute

$$
=\frac{7425}{30}=247 \cdot 5 \text { heat units, }
$$

and the cooling effect that would have been produced by a perfect machine per horse-power per minute $=42 \cdot 733 \times 14=598$ heat units.

The efficiency of the machine was therefore $=\frac{247 \cdot 5}{598}=4$, that of a perfect machine being 1 . 
In answer to a question as to the cost of production by the respective machines,--

Mr. REECE stated that by his machine the cost of cooling a barrel of water through $20^{\circ}$ was $1 \mathrm{~s}$. per 1,000 gallons, and the cost of making a ton of ice, taking coal at $30 \mathrm{~s}$. a ton, was exactly $5 s$. It was, he said, new to him to learn that ammonia machines were worked with 180 or 200 lbs. pressure. Ammonia condensed into a liquid perfectly at a temperature of $68^{\circ}$, and with a pressure of $120 \mathrm{lbs}$. A machine had been running day and night for four months without stopping, except for two hours once a week to change the liquor, and he had never discovered the large losses to which reference had been made.

Mr. SIDDELEY said that the cost of production by his machine was from 15s. to $20 \mathrm{~s}$. a ton, which included every item of expenditure, interest on capital, rent, \&c.; but if the mere fuel and labour expended in the production were taken, the cost would only be from 8s. to 148. per ton, according to the size of machine. With water-power the cost would be from $7 s$. to $10 \mathrm{~s}$, as had been practically demonstrated at Penzance. With regard to the ammonia machine, he had certainly seen one at work at a pressure of $170 \mathrm{lbs}$.

Mr. H. J. WEST said the cost of making transparent ice by his machine was $12 s$. per ton, and opaque ice from $7 s$. to $8 s$. per ton. With large apparatus, say equal to a turn out of 50 tons daily, the cost in both cases would be less.

Mr. Siemens explained that he had no desire to disparage Mr. Kirk's ingenious contrivance-on the contrary, he wished it every success-but he could not help observing upon the drawbacks which he conceived were incidental to the construction of the machines. He admitted that the construction had the advantage of giving a greater amount of power in a limited space than the Windhausen machine, but, as a set off, the greater back pressure or lost effect incidental to the engine must be taken into account. Other speakers had alluded to the thermo-dynamic theory, and had argued that, inasmuch as a unit of heat could only develop 772 units of force, so 772 units of force were necessary to abstract one unit of heat in the production of ice. If the object was to create a unit of heat, he could agree with these remarks, but refrigeration meant only the displacement of heat from one temperature to another, and involved the amount of force necessarily due to that step. In starting from the absolute zero point, water of the ordinary temperature of $60^{\circ}$ was in reality just about $500^{\circ}$ hot; and in depressing this temperature to $10^{\circ}$, work had 
to be accomplished amounting to $\frac{60}{30}$, or but little more than $x^{\frac{1}{0}}$ th of the mechanical equivalent of the heat so transferred. This proposition could be verified by means of two diagrams, one representing the curve of air compression with simultaneous injection of cold water, and the other the air expansion after cooling; the difference of magnitude between the two was only $\frac{1}{10}$ th of the air compression diagram, and $\frac{1}{9}$ th of the air expansion diagram, which latter represented the work of refrigeration which was accomplished. This result followed generally from the formula by Clausius just submitted by Mr. Thomson.

Mr. SIDDELEY remarked that Mr. Kirk's machine did its work well, and he believed it to be the best of its kind, notwithstanding what had been said in favour of Windhausen's machine. Nevertheless, he could still show a decided superiority in favour of the ether process; and in support of this assertion he would give a few particulars of work done. In the summer of 1872 a machine was erected at Messrs. Combe's brewery, Long Acre, for cooling the water used for refrigerating the wort. The water was delivered by the wellpumps to the refrigerator of the machine, where it was cooled, and, by means of a pump attached to the apparatus, was forced through the wort refrigerators up to the tank at the top of the brewery, this tank being about 80 feet above the level of the machine. The water was passed through the machine at the rate of 165 barrels, or 5,940 gallons per hour, and was cooled from $55^{\circ}$ to $47 \frac{1}{2}^{\circ}=7 \frac{1}{2}^{\circ}$. The indicated HP. expended in performing this work was $29 \frac{1}{4}$ HP. with the water-pump standing, and $34 \frac{1}{1}$ HP. with the pumps working; but as the pumping did not strictly belong to the cooling part of the machine, and in this instance was in excess of what was usually required, the first must be taken as the power exerted, in comparing this machine with others. Before entering into this comparison, he would briefly show the advantage of this mode of cooling over the use of ice dissolved in water; or otherwise applied. The heat taken out of the water in passing through the machine, calculated in gallons cooled $1^{\circ}$, was-

165 barrels $\times 36$ gallons $\times 7 \frac{10}{2}=44,532$ gallons.

This brought into heat units, was

$$
44,532 \text { gallons } \times 10 \mathrm{lbs} .=445,320 \text { heat units, }
$$

and this $445,320 \times 24=10,687,680$ heat units abstracted from the water in twenty-four hours.

In a Paper on Artificial Freezing and Refrigeration, ${ }^{1}$ Dr. Paul

1 Vide "Journal of the Society of Arts," December 1Sth, 1868. 
had stated that "the total quantity of heat to be abstracted from water at $60^{\circ}$, in order to produce one ton of ice, is 382,256 heat units." Therefore the heat units abstracted by the machine, divided by this sum, would give the number of tons of ice which, by melting, would be requisite to produce in twentyfour hours the same amount of cooling. This was nearly 28 tons, and it was produced with an expenditure of about one-fourth the power required to make that quantity of ice, while the cooling was more rapidly and efficiently performed. In connection with this subject, he would direct attention to an arrangement adopted by Mr. Wilson, of Messrs. Combe and Co., by which the exhaust steam from the engine of the machine was employed to heat the water used in brewing, say about 1,200 barrels per day, and thus the actual cost of cooling the water for refrigerating was reduced to a minimum. A second machine of the, same size was started during the last season, and the results were equally satisfactory, as also were those from a similar machine erected at Messrs. Bass and Co.'s brewery at Burtonon-Trent. In comparing the performance of this machine with Mr. Kirk's, he thought the fairest way would be to reduce the work done to the number of heat units taken out of the water per HP. per minute; the result was-

\begin{tabular}{|c|c|c|c|}
\hline & & $\begin{array}{l}\text { Siddeley and } \\
\text { Mackity's } \\
\text { Ether Machine. }\end{array}$ & $\begin{array}{l}\text { Kirk's Wet Air } \\
\text { Macbine. }\end{array}$ \\
\hline HP. spent in driving & & . 30 & 37 \\
\hline Quantity? of water cooled & d per minute & - I00 gallons. & 21 gallons. \\
\hline Temperature of Inflow & - & $55^{\circ}$ & $61 \cdot 25^{\circ}$ \\
\hline of Outflow & v. & $47 \cdot 50^{\circ}$ & $47 \cdot 25^{\circ}$ \\
\hline $\begin{array}{l}\text { Heat Units taken out of } \\
\text { per mintite. }\end{array}$ & $\begin{array}{c}f \text { the water pe } \\
\text {. }\end{array}$ & $\left.\begin{array}{l}\mathrm{HP} . \\
\cdot\end{array}\right\} 250$ & 80 \\
\hline
\end{tabular}

or fully three times the amount of work done per HP.

From data obtained from machines employed in ice-making in Glasgow, he was able to make a more complete comparison, and further to show the superiority of the ether machines. These machines were each capable of producing 5 tons of ice per twentyfour hours, and this was done with an expenditure of 20 indicated HP. Their performance might be compared with the dry-air machine, with the following results :- 


\section{IOE-MAKING Temperatures,}

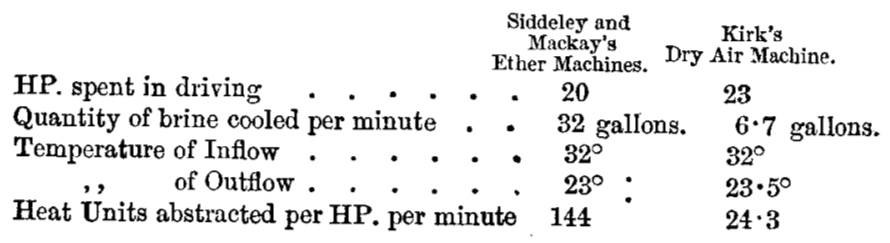

or nearly six times the quantity of cooling.

\section{Cooling Water Temperatures.}

HP, spent in driving Ether Machine. Wet Air Machine.

Quantity of fresh water cooled per minute $\quad 35$ gallons. 21 gallons.

Temperature of Inflow . . . . . $60^{\circ}$ 61.25

,, of Outflow . . . . . . $45^{\circ} \quad 47 \cdot 25^{\circ}$

Heat Units abstracted per HP. per minute $230 \quad 80$

Compared with the wet-air machine cooling at lower temperatures, the proportions would be thus:-

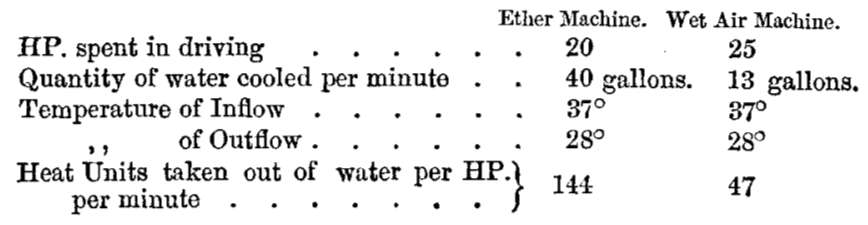

In these two cases the results were in favour of the ether machines in the proportion of three to one. The amount of cooling water required would also make this comparison still more favourable, as the proportion of this would be from a third to one-half the quantity. With reference to Windhausen's machine, it must have been greatly improved since one was exhibited in London, if it would produce ice at anything like the rate stated. At that time he was informed it would make 3 tons of ice per twentyfour hours, or cool 300 gallons of water from $65^{\circ}$ to $40^{\circ}=25^{\circ}$ per hour; but the power required was considerable, which he estimated at from 25 to 30 nominal HP. There was certainly great room for improvement, and he could not conceive how ice could be made so cheaply with it as stated.

Referring to the last machine introduced for producing cold, Mr. Reece's ammonia machine, it did not appear able to work in a satisfactory or reliable manner, from what causes he was not prepared to say. It was almost impossible to compare it with 
the ether machine. It had been stated that ice could be made for less than 5s. per ton; but there was an important omission in that estimate. The cost of producing 50 tons of ice was given, and the water to form the ice was taken into account, but not the cost of water for condensing; and, as the quantity required for this purpose was large, he estimated that this would at least treble the cost of the ice, and raise it to $15 s$. or $20 s$. per ton. For cooling purposes it was apparently a failure. He had just completed the erection of an ether machine to supersede an ammonia machine, which would not perform the work guaranteed by more than one-half, and which was extravagant in cooling water, besides being dangerous from the excessive pressure carried in parts of the machine, and the difficulty experienced in keeping it tight.

Mr. KIRK, in reply, said he assented to the remark, that the efficiency of an air machine became less as the temperature of absorbing heat was lowered, but this was not confined to an air machine. It was a necessary condition of a heat engine, whatever the nature of the medium employed, that the quantity of heat absorbed at any temperature by expansion was in proportion to that temperature expressed in the absolute scale. The same was true of the heat given out by compression. Thus, in a heat engine, containing say $11 \mathrm{~b}$. of air, for a given difference of temperature between that of receiving and rejecting heat, the power would be the same, at whatever part of the thermometric scale these operations took place; but the actual quantity of heat absorbed and rejected diminished as lower temperatures were employed. Thus, the highest temperature of cooling was in practice about $45^{\circ} \mathrm{Fahr} .\left(506^{\circ}\right)$, and the lowest about $15^{\circ} \mathrm{Fahr} .\left(476^{\circ}\right)$; and if in both cases the temperature of rejection of heat was taken at $75^{\circ}$ Fahr. the power required would be, while cooling at $15^{\circ}$, double that required while cooling at $45^{\circ}$, and the heat absorbed or cooling done by the same weight of fluid about 6 per cent: less. The determination of the respective merits of various kinds of machines under different conditions of temperature could not be thus ascertained. In comparing air and ether machines he differed from Mr. Siemens, and maintained that the air machine was working to the best advantage when the difference between the temperatures of absorbing and rejecting heat was large, and the ether machine when that difference was small. In the air machine, when the difference of temperatures was small, the low power which ought to be required to drive the machine, being the difference between the work of compression and of expansion, bore but a low ratio to 
the whole power transmitted through the moving parts of the machine which was the sum of these. Since the loss of power by mechanical friction was that due to the surn of these powers, when the difference of temperature was small this bore a high ratio to the useful work; as the temperature at which expansion took place was lowered, the total friction was slightly diminished, and the ratio of useful work to friction rapidly increased.

In the ether machine compression by external work was to a great extent replaced by condensation, or internal work unaccompanied by friction. In this machine, as a low temperature of evaporation-absorption of heat-was reached, mechanical difficulties rapidly increased, a high vacuum must be main tained, unavoidably accompanied by increased leakage of air ; and although means were provided for removing this air from time to time, it could not be done without a loss of some of the most volatile part of the ether, and a reduction in the efficiency of the machine. On the other hand, if a high temperature of condensation could not be avoided, a pressure in the pump and condenser considerably above the atmosphere must be employed, attended also by a loss, through leakage, of the volatile ether. In addition to these difficulties the ether was gradually deteriorated by the oil used at the stuffing-boxes, and in the cylinder of the pump, and the higher the vacuum required the more rapidly did this take place. Not only did the gradual deterioration of the volatile quality of the ether go on more rapidly at low temperatures than at high, but at low temperatures it had a much more prejudicial effect. Thus the ether machine at Bathgate, while working at about $15^{\circ} \mathrm{Fahr}$, would frequently from these causes have its efficiency reduced one-half.

In his remarks on the unmanageable bulk of air mathines, whether motive power engines or refrigerating machines, $\mathrm{Mr}$. Siemens seemed to have overlooked the fact that in Stirling's engine, and in the machines described, the air was much above atmospheric density. As a matter of fact, in Stirling's engine the mean effective pressure on the piston was fully 37 lbs. per square inch, quite 50 per cent. higher than in the best modern steam engines, and the size of cylinder required in the air engine was proportionately less. Similarly, the air machine was less in bulk than the corresponding ether machine. He considered the application of a regenerator in Stirling's engine, and the whole arrangement of the engine, one of the greatest steps made in scientific engineering in the present century. It was an error to suppose that the utmost possible efficiency of the air in this engine was $\frac{1}{6}$ th. Reference to the full analysis of the performance of this engine, by the late [1873-74. N.S. $]$ 
Professor Rankine, ${ }^{2}$ would show that the efficiency of the air was $\frac{3}{10}$, fully 50 per cent. more than that of steam in the best steam engines. Besides, so far as he was aware, it was the only air engine which, notwithstanding some failures in the heating vessels, had stood the test of working a factory for some years. The superiority of this engine to Ericsson's was obvious; and in adopting an inversion of it in preference to Ericsson's, which he had tried, he considered he had acted wisely.

In a large moist-air machine recently sent abroad, he expected that the coal required would not exceed $4 \mathrm{cwt}$. per ton of ice.

In reply to Mr. West, as to his motive in bringing out an air machine, after using for some time an ether engine, and as to the possibility of risk from fire attending the use of ether being imaginary, he would record the accident which induced Messrs. Young and Meldrum to dispense, if possible, with its use, and to incur the expense of a long and costly series of experiments to find a substitute. There had from the beginning been frequent interruptions to the work, arising from imperfections in the ether boiler and breakage of valve spindles; but the accident which alarmed the firm was the collapse and fracture of the shell of the ether boiler without warning, during the busiest part of the season. Though every precaution was taken, the only light being: a lamp near the door, the heavy ether vapour spread insidiously over the floor, till, reaching the lamp, which was near the ground, it caught fire and covered the whole floor with a carpet of flame. The sight was magnificent while it lasted, which was only for a few moments, and fortunately happening while men were present, the fire was extinguished without damage.

As to the large quantity of cooling water used in the experiments, he would explain that the experiments simply afforded the means of ascertaining the units of rejected heat, which might be made up of more heat and less water, or of less heat and more water. In regard to the comparison made by Mr. Siddeley between the performances of air and ether machines, it must be understood that both the dry-air machine and the wet-air machine quoted were the first of their class, and not the most improved; but they were the only ones of which he could furnish complete results of both absorbed and rejected heat and power, ascertained by continuously repeated measurements and corresponding diagrams. Those who knew the difficulty in getting experiments made with machines

1 Vide "A Manual of the Steam Engine and other Prime Movers," p. 362. 
constantly at work in manufactories, and the time they took, would excuse his not being able to quote more recent performances.

Although the machines of the Glasgow Ice Company, referred to by Mr. Siddeley, were the best specimens of ether machines, and had worked well, the results quoted had not been by any means regularly maintained, owing chiefly to the causes mentioned, and the consumption of ether had been considerable. Besides, a single experiment at $23^{\circ}$ was not a fair test of the power required in making marketable ice, the temperature being for a great part of the time below this. As to the coal used by the machine at Bathgate, he ought to explain that a short egg-ended boiler was used, and that the coal from neighbouring pits was bad and cheap.

The dry-air machine employed in ice-making in China was reported by Mr. Kyle as having required $15 \mathrm{cwt}$. of Formosa coal per ton of ice made; in this case, also, the steam-boiler was of an inefficient type.

Professor C. PIAzzi Surru stated, through the Secretary, that the subject of the mechanical production of cold had been much prosecuted by him from 1846 to 1856 , with more or less .countenance and assistance on different occasions from Mr. James Stirling, Mr. William Petrie, and the late Professor Macquorn Rankine. The special application which he had in view was the cooling of air in rooms, particularly of hospitals in tropical climates, where he had seen something of the waste of European life and energy, which was ever going on there so fearfully though silently, and mainly for want of some domestic application the converse of a fire and a fire-place.

After carrying on some experiments, on a small scale only, Mr. James Stirling kindly favoured him with large engineering drawings of a power-driven air-pump, and a convenient system of self-acting coolers for the hot air of compression. Mr. William Petrie supplied several papers on the methods of escape to be furnished to the cooled air of compression, to prevent its reheating itself in the act of escape. Finally, when Government allowed, towards the end of the Crimean war, a small sum for constructing a cheap model of an air-cooling machine, to be worked only by hand, Professor Macquorn Rankine furnished the design for it, bore part in all the trials with it, and prepared the final report to Government when the apparatus was sent to Chatham in 1856.

The general principle proceeded on was, to pump air under compression into a worm still; to take the heat of compression out of 
it there by conduction through the pipe; to utilize the force of the compressed air, or make it do work in escaping, and then let the cooled and expanded air pass on to the apartments to be cooled. The whole circle of the operations was therefore entirely mechanical; and although in 1852 it had had to compete at the British Association, in description, with what was urged by $\mathrm{Mr}$. William Sykes Ward, of Leeds, and others, in favour of the introduction of physical and chemical forces also-as the employment of sulphuric ether, and continued supplies of freezing salts-both Professor Rankine and he persisted in abiding by the purely mechanical method of acting on air, as being that which would sooner or later become the most sufficient method for the constant work of the future. But neither were altogether content with the results of the large wooden model in 1855-6. To save power, when that had been ordered to be confined to the human hand, Professor Rankine had given the machine the so-called frictionless plungers working in vertical troughs of water; the amount of compression of air thereby possible was a very small part of only one atmosphere. The cooling result expected to be gained had been calculated on closely, and was found, in practice, to be generally almosit entirely overborne by the effects of watery vapour.

Yet there was another drawback to the practical success, which was not suggested till 1861. Having heard that Mr. Kirk had adopted for his air-cooling machine the converse, not of the steanengine, but of Stirling's air-engine, he remembered not only certain advantages in the movement of the regenerator of that engine, acting in place of slide-valves, and in the facilities for keeping watery vapour out of the interior of the machine, and all that it had necessarily to act upon, but also Mr. James Stirling's own emphatic account years before, touching his greatest discovery in working his brother's air-engine as a power-engine, viz., that though everything else might be admirable in its own way, no paying results could be got out of the machine, as a whole, when dealing with air of one atmosphere of pressure only. That the results improved continually as the circulating medium was made more dense, until at ten and twelve atmospheres one horse-power per hour could be got with $3 \mathrm{lbs}$. to $4 \mathrm{lbs}$. of coal. This approached the economy of a good steam-engine, and surpassed the results of many. From that moment he perceived Mr. Kirk had got hold of the right idea; and his practical skill in working it out had been admirable. The scientific problem of air-cooling at least was now solved; there was no longer any mystery, any uncertainty, any difficulty, wherever any customer chose to pay for it. For 
several years past he had recommended all private applicants from India to consult Mr. Kirk; and he was persuaded that, if Her Majesty's Government really desired to have the first element of health for their troops in the tropics-viz., coolness-introduced into the hospitals of both the East and West Indies, it must be by the air-cooling machine.

Mr. Johr D. BarRy furnished, through the Secretary, the following description of Mr. A. H. Tait's compound pneumatic ice apparatus. This process differed materially from those hitherto introduced, avoiding the objectionable use of the chloride of lime, or brine bath; and, where pure water was frozen, furnishing clear ice, in blocks of any thickness required, at a cost not exceeding $8 s$. to $10 s$. per ton, according to the price of coal and labour. The first outlay was less than that for any apparatus yet in the market for the same quantity of ice produced, and the ice was pure, clear, and wholesome. The apparatus consisted of two sets of pumps driven by steam or water power; one set, No. 1, to compress sulphurous acid gas into fluid at a pressure of about 45 lbs. per square inch, or four atmospheres; and the other, No. 2, to compress atmospheric air at a pressure of about $75 \mathrm{lbs}$. per square inch. 'I'o these were added two cylinders furnished inside with pipes, likewise designated Nos. 1 and 2, and an ice box, in which the water to be frozen was congealed by a constant current of cold air, that passed under and over the surface of the water in the vessel placed in the ice box. Sulphurous acid, which was necessary, might be made pure, and economically, by forcing the products of the combustion of sulphur in a suitable furnace into an open vessel containing milk of lime or caustic soda, where the sulphurous acid was retained in the form of sulphite of lime or soda, and the nitrogen, carbonic acid, and undecomposed atmospheric air passed off. The sulphite of lime in its fluid state was then placed in another air-tight wooden vessel, furnished with a vessel at the top to contain sulphuric acid, which was let down as required into the fluid sulphite of lime, in order to set free the sulphurous acid, which should be passed through a close vessel lined with lead, containing sulphuric acid of $66^{\circ}$ Beaumé, so as to deprive the sulphurous acid of vapour of water, which was detrimental in the process. Sulphurous acid might also be made in various other ways, viz., by sulphuric acid and scrap copper, sulphuric acid and charcoal, sulphur and sulphate of iron, with pyrites, etc.; but he preferred the combustion process. The sulphurous acid gas set free by the action of the sulphuric acid on the sulphite of lime now passed to the pumps or compressors 
No. 1, by which it was forced into an upright cylinder filled with tubes of copper wiped outside with a composition of lead and tin, the inside of the cylinder being lined with sheet lead. In to this cylinder outside of the pipes the gas was forced by the pumps No. 1, and was. condensed at a pressure of about 45 lbs. per square inch, aided by a constant stream of cold water which surrounded the cylinder, and also passed through the pipes inside, in order to reduce the gas under compression to the temperature of the water used in cooling. This condensed gas was now let into another cylinder, No. 2, lined with lead inside, and filled with copper pipes, the flow being regulated so as to keep up the pressure in the cylinder No. 1. The copper pipes in No. 2 were also wiped outside with a composition of lead and tin, the gas expanded in this cylinder outside pipes, and after its expansion was again returned to the pumps or compressor No. 1 to be again liquefied and expanded. The compression of the gas in one cylinder and its expansion in the other was therefore continuous, and there was no waste of gas if there were no leaks in the machinery. Liquid sulphurous acid at a temperature of $60^{\circ}$ Fahrenheit boiled at $14^{\circ}$ Fahrenheit, or $18^{\circ}$ below the freezing point of water under ordinary atmospheric pressure; and if allowed to assume the form of gas freely, it converted the fluid left behind into a solid, so great was the reduction of temperature. $\mathrm{He}$ was not aware of any reliable data about the latent heat of evaporation of fluid sulphurous acid, but from the general fact that the latent heat was inversely as the specific gravity of vapours. at their boiling point, he estimated the latent heat of sulphurous. acid at 966 , equal to 214 units of heat. This capacity, coupled with its low boiling point, and the moderate degree of pressure requisite to convert it into fluid, made this gas the most valuable agent for the manufacture of ice in the whole range of chemistry. To compress 1,000 cubie feet of sulphurous acid gas into fluid, and to discharge the same into gas at $45 \mathrm{lbs}$. per square inch above atmospheric pressure, would require a power equal to about $3,700,000$ foot pounds; or, taking the efficacy of the machine at only 50 per cent., $7,400,000$ foot pounds would be required to compress 1,000 cubic feet of gas into $171 \mathrm{lbs}$. of fluid acid, or it would require nearly 6 cubic feet of gas. One HP. would furnish $0.76 \mathrm{lb}$. of fluid acid per minute, equal to $456 \mathrm{lbs}$. in ten hours. One pound of water at $62^{\circ}$ Fahrenheit must have 174 units of heat abstracted to form ice at $32^{\circ}$ Fahrenheit, taking into consisideration unavoidable losses. One pound of liquid sulphurous acid would, by its evaporation, convert $1 \mathrm{lb}$. of water into ico with $1 \mathrm{HP}$, equal to $456 \mathrm{lbs}$. of ice in ten hours. To make 1 ton of ice: 
in ten hours would require $5 \mathrm{HP}$., consuming not more than $350 \mathrm{lbs}$. of coal, or, in other words, in practical work 1 ton of coal would produce from 6 tons to 7 tons of ice.

Mr. Bourne observed that it would be an invidious task to pronounce upon the rival pretensions of the different freezing: machines of which the characteristic features had been expounded; but it might not be inopportune to offer a few general remarks on the subject of refrigeration.

Cold was produced by radiation into space, by the liquefaction. of solids, by the vaporisation of liquids, by the dilatation of gases, and by electricity.

In the upper provinces of India ice was obtained by exposing water, in shallow porous vessels, to the cooling influence of the sky during clear nights. The evaporation from the porous vessels cooled down the water, and the radiation of heat from the surface produced a film of ice, which in the morning was skimmed off and preserved for use. It was a necessary precaution to place the vessels upon a layer of straw, so that they might not be affected by radiation or conduction upward from the earth; and it was also indispensable that the sky should be free from clouds, else the heat was radiated back from the clouds, and freezing did not take place. The operation of the same laws occurred in the deposition of dew. The surface of the earth was cooled by radiation, and the moisture of the air was condensed by the cold surface and precipitated as dew, in the same way in which moisture was precipitated upon the surface of a glass of cold water in summer, or upon the windows of a heated room when the air outside was cold.

If ice at $32^{\circ}$ was heated over a fire, it would take some time to melt, although it had all the while been receiving heat, and although the resulting water was still only at a temperature of $32^{\circ}$. This showed that melting absorbed heat; and when the heat was supplied from any extraneous source the liquefaction was a source of cold. Thus, when certain salts were melted in water cold was produced, and those salts were called freezing mixtures. So also a low temperature resulted. when snow and salt were melted by being mixed together.

The vaporisation of liquids was one of the usual ways of producing cold. In India water was cooled by pouring it into a metal bottle, which was then wrapped in a wet cloth and swung in the sun. The heat and current of air induced rapid evaporation, which cooled the contained water. When the hot winds prevailed in the arid parts of India, houses were cooled by blowing air 
through a thick matting kept constantly wetted with water. The evaporation of the water cooled down the air to an agreeable temperature, and the hotter the wind the greater was its avidity for moisture, and the greater the refrigeration.

The dilatation of gas, as well as the vaporisation of liquids, afforded a powerful refrigerating agent, and one or both of these expedients was called into play in the different freezing machines. In Mr. Kirk's machine atmospheric air was the gas employed. The air was compressed by a piston, by which means the temperature was raised, as in the syringe for lighting amadou tinder by the sudden compression of air. The heated air was cooled by water, and was then suffered to expand, when it sought to recover from surrounding objects the heat it had lost, and thus lowered their temperature.

Electricity was a source of cold not yet developed, but which appeared worthy of attention. More than thirty years ago Peltier, in experimenting on the thermo-electric battery, discovered that cold was produced by a current passing from the bismuth to the antimony. All the freezing machines described in the course of the discussion were virtually thermo-dynamic engines inverted. Such engines uniformly worked with a great loss of effect; and the efficiency of electro-magnetic engines was about four times greater than that of heat engines. A similar relation might, perhaps, hold in the inverted machines.

In all thermo-dynamic machines there must be two temperatures, just as in the generation of power by gravity there must be two levels, and in the subsidence of the weight from the higher to the lower level power was generated. In freezing machines there was only one temperature to begin with, and that had to be raised at one end of the machine, or to be depressed at the other end, by an expenditure of power, just as power had to be expended in winding up a weight. It was a law of thermo-dynamics, that the same quantity of heat, with the same extremes of temperature, would generate the same amount of power, whatever might be the medium through which the heat was made to operate-whether it was steam, or air, or water, or metal, or any other substance. The converse of this proposition would also be true; and just as a given expenditure of heat would produce a corresponding amount of power, so would a given expenditure of power produce a corresponding amount of refrigeration. Excluding details, therefore, and without entering into minutiæ, there was no theoretical reason why one freezing machine should not be as efficacious as another. The difference between them was not so much a differ- 
ence in principle as a difference in cost, or convenience, or safety, or something of that nature. As heretofore constructed, the airmachine appeared to absorb more power to do the same work than some others; but this result he considered accidental to the mode of construction adopted, and that it might be obviated in future examples. If, in point of cost, all the systems were made equalwhich he believed to be the inevitable tendency-then the question of comparative merit would narrow itself to considerations of safety and convenience. He could not assent to the remarks of one of the constructors of ether machines, as to the visionary nature of the apprehensions entertained in regard to the dangers of ether, especially on board ship. A system of supplementing the power of steamers by the employment of ether was, some years ago, proposed by M. Du Trembley, and this system was applied to several steamers by the late Mr. J. W. Jameson, Assoc. Inst. C.E., who had read a Paper on the subject before this Institution, and who had referred to some of the accidents that had occurred. ${ }^{1}$ He did not maintain that the risks of using ether in freezing machines on shore were as great as those arising from its use in engine-rooms at sea; but he thought that all vapours, like those of ether or ammonia, which were infiammable or poisonous, and liable to leakage under high pressures, were objectionable on shipboard, whereas atmospheric air was harmless. He believed, too, it was on board ship that one of the most valuable applications of the freezing machine would yet be found-in enabling frozen meat to be brought from all parts of the world in vessels specially constructed for its conveyance.

Mr. Greaves observed, through the Secretary, that the study of this subject presented at the present time a remunerative field, and one which had not been yet either extensively or profitably worked. The introduction of heat into water had occupied a large share of attention, but to a far less extent the removal of heat from it. There could be little doubt that through the medium of water, and the vapour of water, the greatest mechanical force was attainable; but a point would be gained for a multiplicity of processes if what might be called a dry machine could be produced for propa. gating and communicating reductions of temperature.

Condensation of steam by surface action on the vessel containing it had made considerable advances; but the absorption of heat was still only practically effected by the presence and application of large volumes of water.

1 Vide Minutes of Proceedings Inst. C.E., vol. xviii., p. 233 et. $8 e q$. 
The extent to which the production of cold, either by injection or surface application, was carried, came largely under his notice through his knowledge of the sums annually paid in the East London district for the supply of water, which was applied to no other purpose, and which with the least contamination possible went away to the sewers, merely elevated in temperature a few degrees. The process of sugar making was one in which these practices were peculiarly common; and a sum of at least $£ 10,000$ per annum was paid in the East London Water Company's district in this one line of manufacture. The process of boiling in vacuo had now been practised for about fifty years; but in times quite recent there had been a great endeavour to lower the temperature under which the process was conducted. Sugar was now boiled at a temperature as low as $110^{\circ}$; and when anything near this could be maintained, sugar was made at once into a strong; bright, granular crystalline material, instead of being, as before, carried through the earlier stages of a heavy syrup, to be afterwards clarified and made into loaves. The modern process would not be practicable without the aid of centrifugal machines; but it was the low temperature for boiling which allowed of the light bright colour being preserved, and this low temperature was only obtained by working under a high vacuum, and rapid condensation of the vapour of the syrup was necessary.

In brewing and clistilling, also, large sums were annually expended in maintaining low temperatures, not only to condense the fumes of the spirits, and expedite the out-turn fron any stated quantity of factory plant, but to maintain quality, flavour, and even soundness in many liquors, on which in the process of making even atmospheric temperature exercised a prejudicial effect.

All these were processes to which the supply of cold came most advantageously, and with a value in the goods apart from any share as a source of power.

As a source of power, however, the ease and rapidity of condensation were far behind what was desirable in order that the value of the machine, both mechanically and commercially, might be increased. The temperature of the whole sea in the Bay of Bengal was for months as high, or higher, than that of the condensed water or hot well of a steam-engine in northern climates, when even good proportions had been adopted; and many a steamer, that ran at a high velocity and made excellent passages across the North Atlantic, was a tub in tropical seas, not only through the defect of vacuum, but by the unfair labour thrown upon a surcharged airpump lifting and foreing over crooked passages, and through the 
ship's side, streams for which the apertures were not adapted, and with strains to which the parts were not designed.

If cold could be produced it could be maintained; and the storage of a negative power in the form of ice was attended with neither danger nor expense. Under any circumstances storage might come in aid of continuous production, and a stream of cold would strengthen greatly the condensing power of natural water in innumerable instances.

These remarks were only made in a desultory manner. The equivalents of heat and cold in their innumerable effects might be determined as sources of power above and below the datum of atmospheric pressure, and above and below the standard average temperature of any place to which a question might have reference.

January 27, 1874.

THOMAS E. HARRISON, President, in the Chair.

The discussion upon the Paper, No. 1,364, "On the Mechanical Production of Cold," by Mr. A. C. KIRK, was continued throughout the evening. 